\title{
Joachim Schmidt-Salzer
}

Produkthaftung im französischen, belgischen, deutschen, schweizerischen, englischen, kanadischen und us-amerikanischen Recht sowie in rechtspolitischer Sicht 



\section{Produkthaftung}

im französischen, belgischen, deutschen, schweizerischen, englischen, kanadischen und us-amerikanischen Recht sowie in rechtspolitischer Sicht

\section{von \\ Dr. Joachim Schmidt-Salzer}

Rechtsanwalt in Braunschweig 
ISBN 3805904258

(C) 1975 by J. Schwcitzer Verlag, Berlin.

Alle Rechte, insbesondere das Recht der Vervielfältigung und Verbreitung sowie der Übersetzung, yorbehalten. Kein Teil des Werkes darf in irgendeiner Form (durch Photokopie, Mikrofilm oder ein anderes Verfahren) ohne schriftliche Genehmigung des Verlages reproduziert oder unter Verwendung elektronischer Systeme verarbeitet, vervielfältigt oder verbreitet werden.

Satz und Druck: Mercedes-Druck, Berlin - Bindearbeiten: Wübben, Berlin Printed in Germany 
Meinem verehrten Seniorpartner, Rechtsanwalt und Notar

Dr. ERICH MEYERHOFF, der mir neue Horizonte eröffnete 
